\title{
APLICAÇÃO DO MÉTODO SLP PARA MELHORIA DO ARRANJO FÍSICO: ESTUDO DE CASO EM UMA EMPRESA DO RAMO ALIMENTÍCIO
}

\author{
Natália Pereira França Vieira (UFRN, Brasil) nataliapfvieira@gmail.com \\ Fernanda Kivia Agra Fernandes (UFRN, Brasil) fernandakiviaf@gmail.com \\ Larissa Rodrigues Cortez (UFRN, Brasil) larissaedaraujo@yahoo.com.br \\ Artur Medeiros de Araújo Nunes (UFRN, Brasil) arturmedeiros.pj@gmail.com. \\ Larissa Elaine Dantas de Araújo (UFRN, Brasil) larissarcortez@gmail.com
}

\begin{abstract}
Resumo: Este estudo objetivou desenvolver o processo de montagem de marmitas em uma empresa do setor alimentício, obtendo melhorias de fluxo por meio de mudança no arranjo físico e padronização de atividades. Para tanto, foram feitas observações in loco e simulações do processo suportando a posterior utilização do método SLP (Systematic Layout Planning - Planejamento Sistemático do Arranjo Físico) para proposição de melhorias no processo. Os resultados mostram que a realocação das estações de servir e mobiliário de apoio constitui a opção de mudança mais viável e de curto prazo. Visto que os ambientes em estudo - recepção, área de montagem e despensa - apresentam maiores limitações para mudança. Além disso, a padronização do fluxo associada a essa mudança contribuem para a melhoria da eficácia do arranjo físico pela redução da necessidade de deslocamento em $25,32 \%$, passando de $1.320,96$ metros para 986,46 metros.
\end{abstract}

Palavras-chave: SLP. Arranjo físico. Setor alimentício.

\section{Introdução}

O arranjo físico de uma operação produtiva preocupa-se com o posicionamento físico dos recursos de transformação, podendo ser considerado o responsável pela tomada de decisão de onde e como alocar as instalações, equipamentos, máquinas e a mão-de-obra.

Um restaurante que vende comida a quilo e porções para marmita, por exemplo, utiliza uma espécie de linha de montagem de pratos, em que, tanto o cliente realiza parte do proces- so produtivo ao seguir a fila e se abastecer dos alimentos desejados, quanto os funcionários, os quais são responsáveis pelo abastecimento e montagem de marmitas e quentinhas.

No entanto, é bastante comum observar em organizações do ramo de serviços alimentícios, operações com longo tempo de processamento, existindo o estoque desnecessário de materiais, além da formação de filas de clientes ao longo da operação. O arranjo físico inadequado apresenta fluxos imprevisíveis e de alto custo, gerando inúmeras inconveniências tanto para clientes, como para os próprios funcionários. 
Sendo assim, o trabalho tem como objetivo desenvolver o processo de montagem de marmitas em um restaurante localizado na cidade de Natal-RN, com o intuito de melhorar o fluxo do processo através de uma mudança no arranjo físico e padronização. Para nortear o estudo, foi utilizado o método do Planejamento Sistemático de Layout, originalmente conhecido como SLP - Systematic Layout Planning, proposto por Muther (1973, apud SANTOS; GOHR; LAITANO, 2012).

Este consiste numa técnica bastante aplicada na indústria de manufatura, voltada, principalmente, ao projeto e à análise de layouts industriais. Para que o sistema SLP pudesse ser aplicado no setor de serviços, foram feitas algumas adaptações ao modelo original de Muther (1973, apud SANTOS; GOHR; LAITANO, 2012). Contudo, antes de descrever o processo de aplicação do SLP, é necessário entender como esse modelo funciona, assim como, os seus princípios básicos. Esses assuntos serão abordados na terceira seção do artigo - Método de Pesquisa.

Em seguida, apresenta-se o estudo de caso, relatando como o processo é realizado na marmitaria e as propostas de melhoria após a aplicação do modelo, destacando seus principais resultados. Na seção conclusão, ressaltamse as principais considerações acerca do trabalho realizado, discutindo limitações e as sugestões desencadeadas a partir dos resultados obtidos.

\section{Referencial Teórico}

\subsection{Arranjo Físico}

De acordo com Slack (2009), arranjo físico é a forma como os recursos transformadores são posicionados uns em relação aos outros, como as várias tarefas da operação são alocadas a esses recursos e de que maneira eles fluem através dos processos.

As decisões sobre arranjo físico são importantes, pois, segundo Moreira (2012), elas afetam a capacidade da instalação e a produtividade das operações, e as mudanças no arranjo físico podem implicar dispêndio de dinheiro, elevados custos e/ou dificuldades técnicas para futuras reversões, além de interrupções indesejáveis no trabalho.

Ressalta-se ainda que a compreensão de aspectos competitivos é de fundamental importância, pois representa um excelente ponto de partida para se chegar a uma ou mais proposições de arranjo físico com bom potencial para satisfazer as necessidades competitivas da empresa (FUSCO; SACOMANO, 2007).

Outro fator que está relacionado com o arranjo físico é o tipo de processo. Pode-se afirmar que para iniciar o processo de arranjo físico, devese, primeiramente, conhecer o tipo de processo que será utilizado, pois cada tipo de processo pode adotar diferentes tipos básicos de arranjo físico (FUSCO; SACOMANO, 2007).

\subsection{Tipos de arranjo físico}

Slack (2009) afirma que a maioria dos arranjos físicos deriva de quatro tipos básicos: arranjo físico posicional; arranjo físico funcional; ar- 


\section{ReLAlnEP}

ranjo físico celular; arranjo físico por produto. Esses estão relacionados com os tipos de processos.

\subsubsection{Arranjo físico posicional}

Nesse arranjo físico, "os recursos transformados não se movem entre os recursos transformadores" (SLACK, 2009, p.185), ou seja, o produto em transformação permanece fixo (ou quase fixo) enquanto as pessoas, as ferramentas e os materiais se movem em torno desse.

\subsubsection{Arranjo físico por produto}

Moreira (2012) afirma que este arranjo físico é usado quando se requer uma sequência linear de operações para fabricar o produto ou prestar o serviço. Dessa forma, cada centro de trabalho se torna responsável por uma parte especializada do produto ou serviço. Além disso, os recursos transformadores são alocados de acordo com a melhor conveniência do recurso em transformação (SLACK, 2009).

\subsubsection{Arranjo físico celular}

Segundo Slack (2009) neste tipo de arranjo físico, os recursos transformados que entram na operação são pré-selecionados e destinados para uma parte específica da operação (ou célula), onde se encontram todos os recursos transformadores necessários para atender a suas necessidades imediatas de processamento. Essa célula pode ser arranjada como um anjo físico por processo ou por produto. Além disso, depois de os recursos transformados serem processados em uma célula, podem prosseguir para outra (FUSCO; SACOMANO, 2007).

\subsubsection{Arranjo físico misto}

Este combina elementos de alguns ou de todos os tipos básicos de arranjo físico, ou usam tipos básicos de arranjo físico de forma "pura" em diferentes partes da operação (SLACK, 2009).

\subsubsection{Arranjo físico por processo (funcio-} nal)

Slack (2009) explica que esse tipo de arranjo físico se conforma às necessidades e conveniências das funções desenvolvidas pelos recursos transformadores que constituem os processos. Assim, diferentes produtos ou clientes terão diferentes necessidades, logo, percorrerão roteiros distintos através da operação. Por esse motivo, o padrão de fluxo na operação será bastante complexo (FUSCO; SACOMANO, 2007).

Neste caso, a abordagem desenvolvida por Muther (1973, apud SANTOS; GOHR; LAITANO, 2012) é muito útil, a qual recebe o nome de SLP (Systematic Layout Planning).

\subsection{O método SLP}

Em busca de uma abordagem estruturada, o Planejamento Sistemático de Layout (Systematic Layout Planning) representa uma metodologia que tem uma grande aplicabilidade no projeto e no reprojeto de layout, especialmente em layouts funcionais. 


\section{ReLAInEPI}

Portanto, o presente trabalho, que se baseará na utilização do método SLP como suporte técnico para tomada de decisão, descreve, a seguir, as etapas necessárias para realização da pesquisa.

\section{Método de pesquisa}

O presente trabalho compreende um estudo descritivo, exploratório, quantitativo e qualitativo, sendo realizado numa empresa do setor alimentício, com o intuito de estudar com maior profundidade os aspectos relacionados ao arranjo físico por processo.

Por conseguinte, os procedimentos metodológicos fundamentaram-se no modelo de processo criado por Muther - SLP (Systematic Layout Planning) - o qual consiste na sistematização da estrutura de etapas, do modelo de procedimentos e uma série de convenções para identificação, avaliação e visualização dos elementos e das áreas envolvidas no planejamento.

O estudo teve início a partir da definição do objeto de estudo e, consequentemente, do tipo de arranjo físico que o caracteriza. Foram realizadas visitas iniciais para compreender como a empresa está organizada. Paralelamente, foram elaboradas perguntas direcionadas ao foco do trabalho, que facilitaram o desencadeamento deste.

Além disso, pôde-se observar, em horários de alta e baixa demanda, todas as atividades desempenhadas pelos funcionários no ambiente produtivo da marmitaria e, assim, quantificar os fluxos existentes, além de mapear o espaço físico, para posterior planejamento do arranjo físico aperfeiçoado.

Para garantir isso, calculou-se a eficácia do arranjo físico atual e do proposto a partir da Equação (1), onde $\mathrm{T}_{\mathrm{ij}}$ é o número de transporte ou movimentações entre seções i e j, por período e $\mathrm{D}_{\mathrm{ij}}$ a distância entre as seções i e j. Quanto menor a eficácia, melhor a eficiência do arranjo.

$$
E=\sum T i j x D i j, i \neq j
$$

$\mathrm{O}$ projeto teve embasamento em pesquisas bibliográficas direcionadas a metodologia do Planejamento Sistemático de Layout. As cinco etapas do método em estudo foram utilizadas como guia para execução do presente trabalho e serão apresentadas a seguir com base na aplicação proposta por Muther (1961, apud SILVA; BANDEIRA; BARBALHO, 2010).

\subsection{Etapa 1: análise dos fluxos dos pro- dutos ou recursos}

Nesta, ocorre a discriminação de cada processo e seus respectivos fluxos de materiais em volume, buscando-se obter uma visão geral da atividade. Para isso, o diagrama "de - para" é utilizado na exposição desses dados, levando em consideração o fluxo, a inter-relação e o volume produzido em cada processo.

Após a definição dos fluxos de cada parte do processo, são estabelecidas prioridades para proximidade entre os estágios de produção. 


\section{ReLAlnEP}

\subsection{Etapa 2: identificação e inclusão de fatores qualitativos}

Esta etapa relaciona todas as partes envolvidas em cada processo, por meio de um diagrama de relacionamento das atividades, o qual apresenta, com base na classificação qualitativa e quantitativa das inter-relações entre os estágios do processo, as prioridades de proximidade entre os estágios de produção.

No diagrama, cada letra corresponde a um grau de inter-relação. Assim, 'A' significa que a proximidade entre os locais é absolutamente necessária; 'E' representa uma proximidade especialmente necessária; 'I' é uma proximidade importante; 'O' constitui que a proximidade é regular; Já o 'U' denota que a proximidade é não importante; $E$ por fim, dá-se ' $X$ ' para proximidade indesejável.

\subsection{Etapa 3: avaliação dos dados e ar- ranjo de áreas de trabalho}

Com os resultados da etapa 2, elabora-se um diagrama de arranjo de atividades que é representado por linhas ligando as etapas dos processos entre si. As partes do processo que envolverem as linhas mais espessas terão que estar mais próximas, pois essas são utilizadas para demonstrar grandes fluxos.

\subsection{Etapa 4: determinação de um plano de arranjo dos espaços}

Para a elaboração de um plano de arranjo físico é necessário que se leve em consideração as dimensões e áreas de ocupação de cada parte do processo, de acordo com os tamanhos proporcionais ao arranjo físico real.

\subsection{Etapa 5: ajuste do arranjo no espaço disponível}

Por fim, ocorre a elaboração do arranjo físico, com base nos resultados obtidos nas etapas anteriores, levando-se em consideração o espaço disponível. Ao final do ajuste, o modelo atual é comparado com o modelo proposto em termos de eficácia e eficiência produtiva.

\section{Estudo de Caso}

Esta seção apresenta o objeto de pesquisa, os dados coletados - de acordo com a metodologia descrita -, as análises dos dados e resultados do desenvolvimento realizado.

\subsection{Objeto de Pesquisa}

A empresa em estudo é localizada na cidade de Natal/RN. Ela se insere no setor alimentício, possuindo os serviços de self-service e marmitaria, sendo o último serviço o foco do presente trabalho. Seus aspectos competitivos são a qualidade e variedade de pratos oferecidos. Para isso, a marmitaria dispõe de um cardápio diferente para cada dia da semana, variando principalmente os tipos de arroz, feijão, macarrão e carnes.

Atualmente, a empresa é formada por 12 funcionários, sendo um administrador/proprietário, um supervisor, 2 cozinheiros, 2 garçons, 5 auxiliares de cozinha e um ASG. Além disso, a empresa desenvolve sua atividade de montagens de marmitas em uma área de 


\section{ReLAInEP}

aproximadamente $38 \mathrm{~m}^{2}$, desconsiderando a cozinha (esta fornece a comida tanto para a marmitaria, quanto para o self-service), como mostra a Figura 2.

FIGURA 2: PLANTA BAIXA DO LOCAL

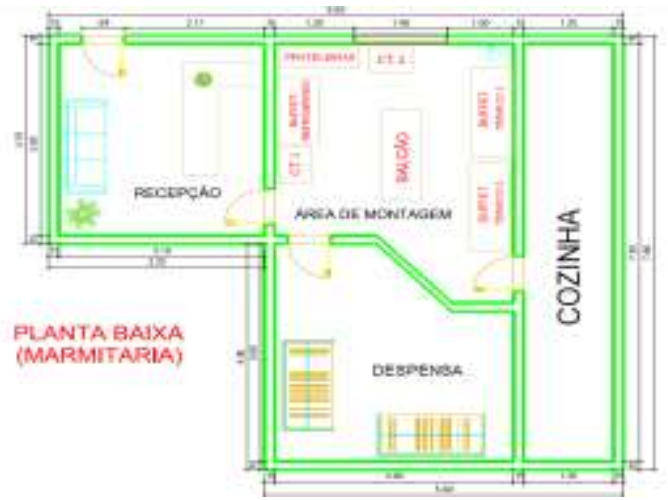

Fonte: Autoria própria (2013)

Como o objetivo desta pesquisa é melhorar o fluxo do processo através de uma mudança no arranjo físico, é importante entender como esse ocorre. Observando o fluxograma (Figura 3), percebe-se que o processo é iniciado com o pedido do cliente e, para isso, há duas opções: o cliente ligar ou comparecer com o recipiente. Além destes, há ainda aqueles clientes fixos, que compram a marmita todos os dias. Estes já deixam os seus recipientes na empresa, que faz entrega em domicílio. Após a realização do pedido, este é enviado para a área de montagem da marmita e sua montagem é iniciada.

Para isso, não há uma ordem a ser seguida, ou seja, não há padronização nesse processo. Logo, o auxiliar de cozinha monta a marmita da forma que lhe é conveniente. Em seguida, o produto é entregue ao cliente, caso este esteja esperando ou, caso contrário, o produto montado é armazenado em caixas térmicas para entregar quando o cliente chegar ou ser entregue pelo motoqueiro.

\section{FIGURA 3: FLUXOGRAMA DO PROCESSO}

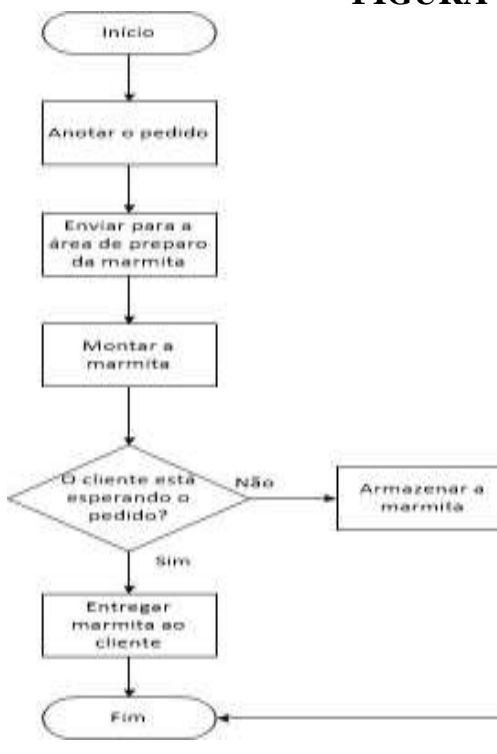

Fonte: Autoria própria (2013)

\subsection{Coleta de Dados}

Com o entendimento do processo, torna-se possível analisá-lo e estudar formas de melhorá-lo. Para isso, seguiremos as etapas do método SLP como ferramenta sequencial para apresentação dos dados coletados. Contudo, é váli- 


\section{ReLAInEP}

do ressaltar que devido as características próprias do sistema estudado, a etapa 4 do método (determinação de um plano de arranjo dos espaços) não pôde ser desenvolvida no trabalho, sendo apresentas, a seguir, as etapas 1, 2, 3 e 5 .

4.2.1 Etapa 1: Análise dos fluxos dos produtos ou recursos

Nesta, desenvolveu-se a análise de fluxos através de observações. Para tal, usou-se a matriz De-Para mostrado na Figura 4, que apresenta os fluxos existentes entre os setores (ou postos de trabalho).

FIGURA 1: MATRIZ DE-PARA

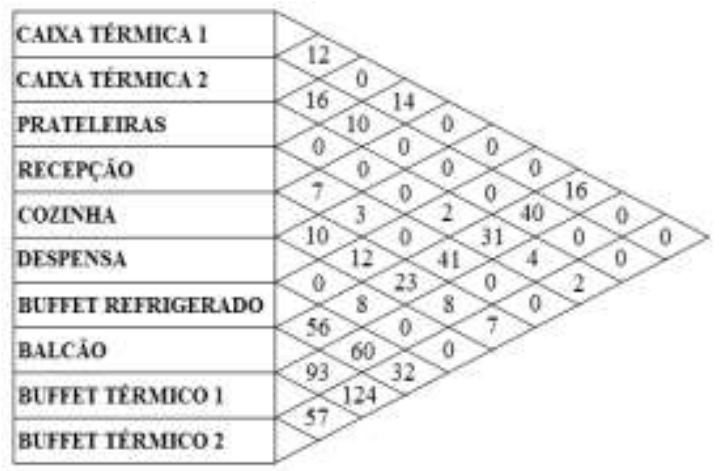

Fonte: Autoria própria (2013)

Observando os dados desse diagrama, percebemos que os maiores fluxos estão entre os buffets térmico 1, buffet térmico 2, buffet refrigerado e o balcão. Ou seja, esses são os locais que merecem maior atenção e são mais significativos no sistema.

\subsubsection{Etapa 2: Identificação e inclusão de} fatores qualitativos

A partir da etapa anterior, torna-se possível identificar e avaliar os fatores qualitativos, elaborando, assim, o diagrama de relacionamento das atividades. Este permite identificar as proximidades necessárias ou não entre os setores, conforme a Figura 5.

\section{FIGURA 5: MATRIZ DE RELACIONAMEN- TO DAS ATIVIDADES}

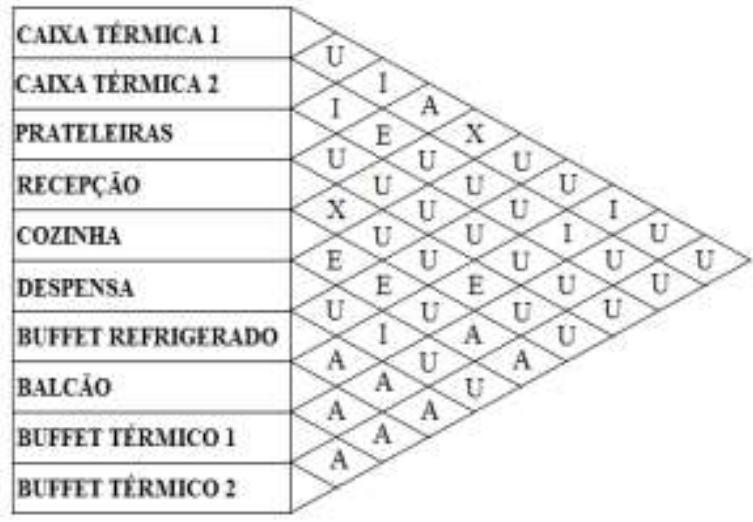

Fonte: Autoria própria (2013)

Essas relações são importantes, pois representam orientações para as futuras mudanças. Como a letra A representa proximidade absolutamente necessária entre os locais, nota-se a importância dos buffets estarem perto do balcão e entre si, assim como os buffets térmicos próximos da cozinha. Já a letra $\mathrm{X}$, que representa uma proximidade indesejável, demonstra a relação entre a caixa térmica 1 e a recepção, e a caixa térmica 1 e a cozinha. Em ambos os casos, essa relação foi estabelecida pelo fato do motoqueiro ter acesso a essa caixa térmica, não sendo interessante ele entrar em contato com a área de montagem e/ou a cozinha, ou seja, com a comida.

\subsubsection{Etapa 3: Avaliação dos dados e ar- ranjo de áreas de trabalho}

Esta consiste em avaliar os dados e elaborar o novo arranjo de áreas de trabalho. Assim, 


\section{ReLAInEPI}

construiu-se o diagrama de inter-relações da Figura 6 relacionada aos dados apresentados na Tabela 1, que mostra visualmente os fluxos entre os locais da marmitaria.

Na convenção do SLP, as linhas mais espessas representam os fluxos mais intensos entre os locais, que nesse estudo, foi adotado como aquelas que possuem um fluxo maior do que 50 deslocamentos entre as áreas de trabalho por dia. Já as relações que possuem um fluxo entre 20 e 50 deslocamentos foram consideradas como as relações intermediárias (não muito fracas e também não muito fortes), as quais foram representadas com uma linha menos espessa do que a anterior, porém, não tão fina quanto aquelas que representam os fluxos menores que 20 deslocamentos.

\section{FIGURA 6: DIAGRAMA DE INTER- RELAÇÕES}

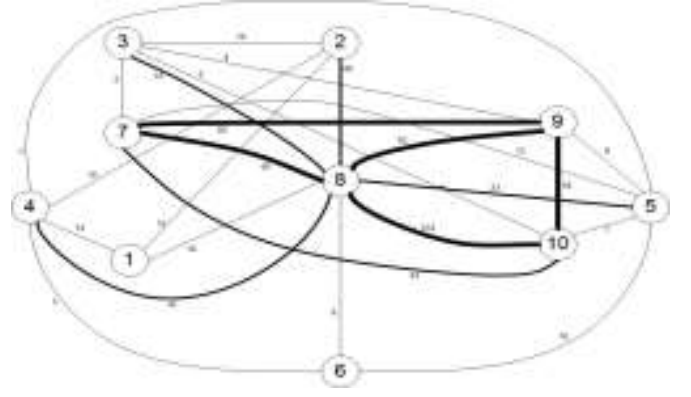

Fonte: Autoria própria (2013)

\section{TABELA 1: LEGENDA DO DIAGRAMA DE} INTER-RELAÇÕES

\begin{tabular}{|c|c|c|c|}
\hline \multicolumn{4}{|c|}{ LOCAIS } \\
\hline 1 & $\begin{array}{c}\text { Caixa Térmica 1 } \\
\text { (CT 1) }\end{array}$ & 6 & Despensa \\
\hline 2 & $\begin{array}{c}\text { Caixa Térmica 2 } \\
\text { (CT 2) }\end{array}$ & 7 & $\begin{array}{c}\text { Buffet Re- } \\
\text { frigerado }\end{array}$ \\
\hline 3 & Prateleiras & 8 & Balcão \\
\hline 4 & Recepção & 9 & $\begin{array}{c}\text { Buffet Tér- } \\
\text { mico 1 }\end{array}$ \\
\hline 5 & Cozinha & 10 & $\begin{array}{c}\text { Buffet Tér- } \\
\text { mico 2 }\end{array}$ \\
\hline
\end{tabular}

Foi possível tirar algumas conclusões com a análise do diagrama de inter-relações, pois ele mostra quão próximo um local deve estar do outro a partir das suas ligações. Para essa análise, devemos considerar que algumas das instalações são fixas (recepção, cozinha e despensa) e não podem ser realocadas.

Além disso, ficou claro que o balcão deve estar no centro do layout, pois quase todos os outros locais têm fortes ligações com ele. Percebeuse, também, que as prateleiras possuem poucos fluxos e que os fluxos entre os buffets térmicos e o refrigerado é intenso, porém eles estão distantes uns dos outros.

Outra informação relevante é a eficácia do arranjo físico. Para o seu cálculo, além dos dados dos fluxos, torna-se necessário conhecer as distâncias percorridas entre os locais (considerando zero quando não houve fluxo), as quais são descritas na Figura 7, que está na escala de metros.

FIGURA 7: DISTÂNCIAS ENTRE AS SEÇÕES

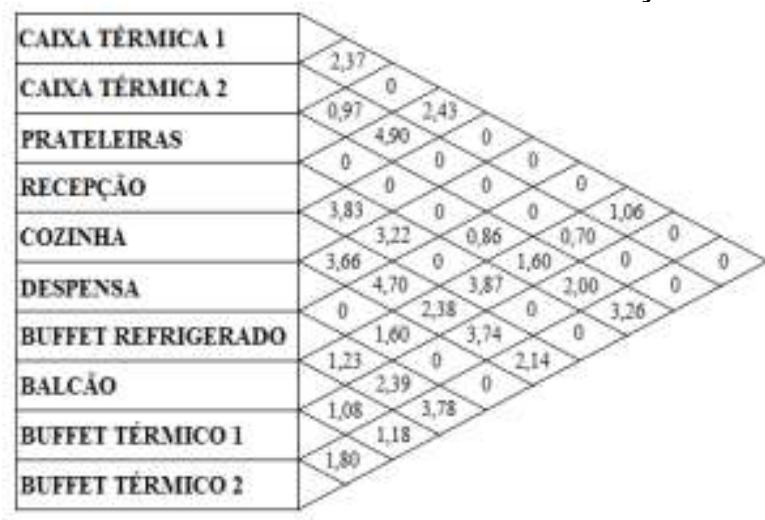

Fonte: Autoria própria (2013)

Assim, aplicando os dados na Equação (1), encontra-se que a eficácia do arranjo físico atual é 1.320,96 metros. 


\section{ReLAlnEP}

4.2.4 Etapa 5: Ajuste do arranjo no espaço disponível

A elaboração desta etapa necessita refazer todas as etapas anteriores considerando a padronização dos processos, de modo a melhorar a disposição dos equipamentos, materiais e pessoas. Para melhor visualização, ele será exibido como o tópico de análise de dados e resultados mostrados a seguir.

\subsection{Análise de dados e resultados}

De acordo com o diagnóstico feito na empresa a partir das observações e da elaboração e análise da matriz De-Para, da matriz de Relacionamento das Atividades e do diagrama de Inter-Relações, concluiu-se que é necessário haver uma melhoria no fluxo do processo de montagem.

Para isso, padronização do fluxo juntamente com a realocação dos objetos, se mostrou a melhor e mais viável opção para ser implantada em curto prazo, aumentando o aproveitamento do local e melhorando a produtividade e a resposta ao cliente.

Para padronizar o fluxo, ou seja, uniformizar o processo produtivo, torna-se fundamental que cada colaborador fique responsável por montar a marmita, fazendo com que esses passem por todas as etapas de montagem, evitando que se esbarrem e que tenham que ir até determinado buffet mais de uma vez em uma mesma execução de montagem. Seguindo, então, uma linha de processo, diante da qual o colaborador sairá do balcão central com a marmita vazia e com a comanda do pedido selecionado pelo cliente e passará pelos buffets térmicos e depois pelo buffet refrigerado, indo por fim até a caixa térmica 1 ou 2 para deixar a marmita pronta. Antes disso, torna-se necessário, em alguns casos, passar pelo portador de sacos para colocar a marmita (quando esta for de alumínio) dentro do mesmo. Essa sequência não impede que cada funcionário passe mais de uma vez pelo balcão central, já que este é o ponto de apoio para o fechamento das marmitas e para a obtenção dos demais materiais necessários.

Essa proposta de padronização está atrelada a uma possível mudança na ordem das opções do cardápio, para que a sequência de montagem esteja de acordo com a ordem das alternativas selecionadas pelo cliente. Ou seja, no cardápio deverá conter as opções começando pelos alimentos presentes no buffet térmico 2, em seguida com as opções do buffet térmico 1 e, por fim, com as do buffet refrigerado. Isto fará com que o funcionário leia as escolhas do cliente e a partir dessa mesma ordem vá preenchendo as marmitas, sem sair da sua linha de processo de montagem já estabelecida pelo novo arranjo físico.

Para estabelecer um melhor arranjo físico, elaborou-se uma nova matriz De-Para (Figura 8) através de uma estimativa dos fluxos baseada na demanda de marmitas por dia, que gira em torno de 86. É importante ressaltar que ao invés do nome 'prateleiras' usado na matriz da Figura 4, empregou-se apenas porta sacos para elaboração desta nova matriz, pois através das observações, concluiu-se que o fluxo entre os postos de trabalho e as prateleiras acontecia apenas para a utilização de sacos, assim, para 


\section{ReLAInEP}

melhor aproveitamento do local, notou-se a necessidade de tirar as prateleiras da área de montagem.

FIGURA 8: MATRIZ DE-PARA ESTIMADO

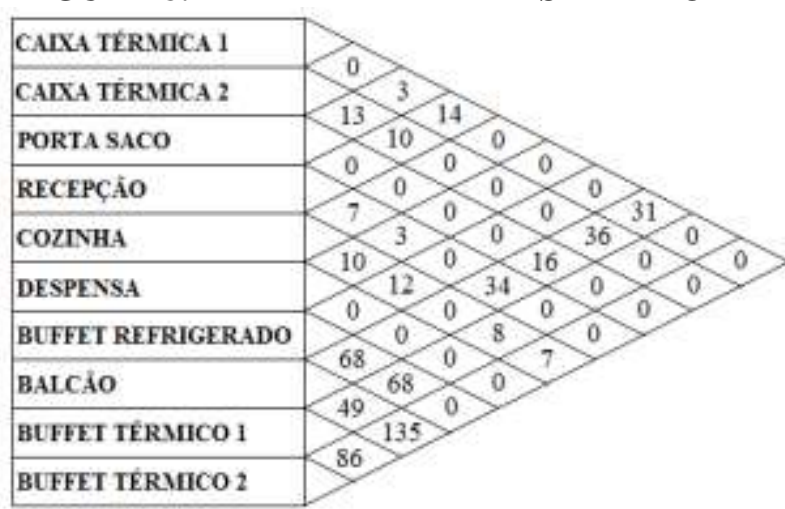

Fonte: Autoria própria (2013)

Com isso, é possível se chegar as principais modificações físicas que devem ser feitas, que são: aproximar o buffet refrigerado dos buffets térmicos (1 e 2), mantendo estes, por sua vez próximos a cozinha, já que contêm alimentos quentes; deixar a caixa térmica 1 e a caixa térmica 2 juntas, mantendo a primeira sempre próxima à porta para impedir que o motoqueiro, que recolhe dela e faz as entregas, entre em contato com a área de montagem e a cozinha, evitando possíveis contaminações.

Além disso, o principal objeto que deve permanecer no centro desse setor específico é o balcão, pois esse possui forte relação com todos os outros objetos presentes na área. A prateleira que está presente no setor de montagem deve ser realocada na despensa, almejando com isso um ganho no espaço físico. Por fim, o porta sacos seria alocado ao lado da caixa térmica 2.

Através dessas conclusões, construiu-se o diagrama de inter-relações da Figura 9.
FIGURA 9: DIAGRAMA DE INTERRELAÇÕES PROPOSTO

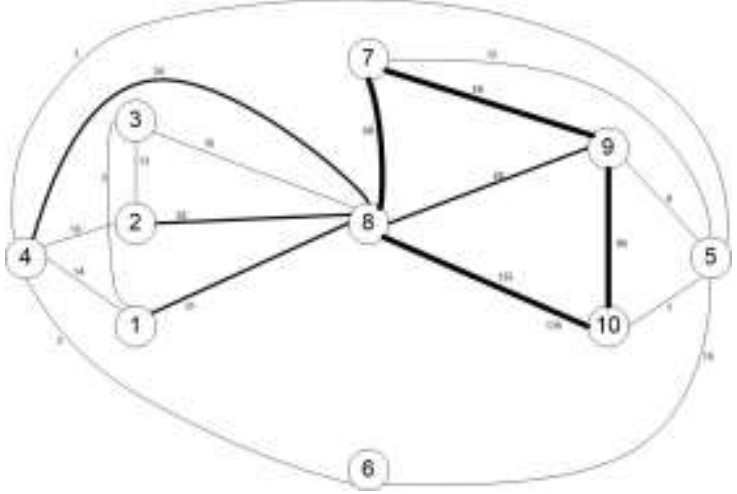

Fonte: Autoria própria (2013)

Observa-se que ele está bem menos poluído que o diagrama da Figura 6, já deixando claro, assim, a melhoria do fluxo do processo. Essas mudanças podem ser mais bem visualizadas de acordo com a redefinição do arranjo físico observado na Figura 10.

\section{FIGURA 10: PLANTA BAIXA PROPOSTA}

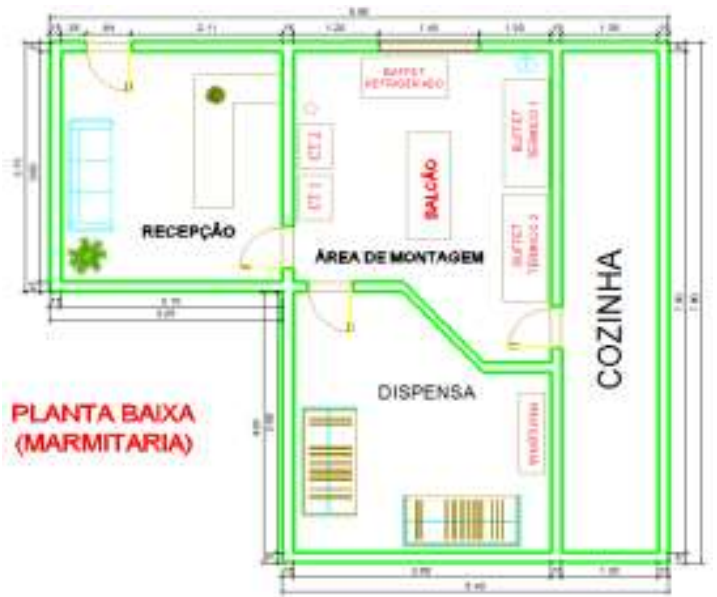

Fonte: Autoria própria (2013)

Após as mudanças propostas na disposição dos equipamentos e uma padronização do processo de montagem, torna-se importante calcular a eficácia do arranjo físico proposto, para confirmar sua otimização. Para isso, foi elaborada uma nova matriz de distância (Figura 11), em seguida, foi calculada a nova eficácia esperada/estimada. 


\section{ReLAInEP}

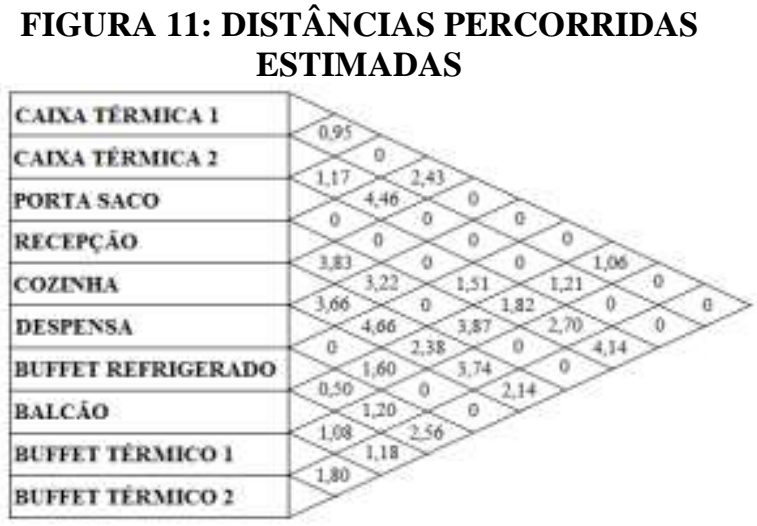

Fonte: Autoria própria (2013)

Assim, aplicando os valores na fórmula da Figura 1, encontrou-se uma eficácia de arranjo físico igual a 986,46 metros. Dessa forma, notou-se que a eficácia reduziu 334,50 metros, significando aumento da eficiência do sistema.

\section{Conclusões}

Atualmente, o setor alimentício conta com uma crescente demanda de consumidores, que exigem um atendimento bom e rápido, eficiente de forma geral, e uma melhor qualidade nos alimentos, principalmente devido à rotina de vida da população estar cada vez mais comprometida pela falta de tempo.

De acordo com a análise dos dados e as observações, foi possível perceber que o problema se enquadrava no desenvolvimento de um estudo referente ao arranjo físico por processo, no qual foi utilizado o método SLP, responsável por melhor ajustar o arranjo no espaço disponível.

Porém, algumas possíveis limitações foram encontradas, devido à existência de áreas mal elaboradas como a recepção, a cozinha e a despensa, que não podem ser realocadas por serem instalações fixas que exigiriam custos elevados à Organização, tanto pelo fato de precisarem ser reprojetadas, quanto pelo prejuízo em parar a produção devido uma suposta reforma. Por isso a melhor alternativa estava em apenas realocar os componentes do setor de montagem, para um melhor ganho no espaço físico do local que possui uma área bastante restrita.

Considerando a situação da empresa após as melhorias propostas, espera-se que essa possa dar continuidade as mudanças préestabelecidas, para que o fluxo de montagem permaneça sistematizado da melhor forma que foi realocado diante do arranjo físico. Sendo o modelo de pesquisa desenvolvido nessa análise - SLP, imprescindível para a garantia de uma maior agilidade ao processo, facilitando seu fluxo entre materiais e funcionários.

\section{Referências}

FORMIGA, F. O. N. Fornecimento de refeições em marmita. SEBRAE. Disponível em $<$ http://m.sebrae-sc.com.br/SebraeSite-

Wap/ideiasdenegocio.id.logic?id=304EC839A02B5 8448325799800690836> Acesso em: 20 abril 2013.

FUSCO, J. P. A.; SACOMANO, J. B. Operações e Gestão Estratégica da Produção. São Paulo: Arte \& Ciência, 2007.

MENDONÇA, M. M. F.; JOSÉ, E. B. S.; COSTA, S. R. R. Estudo da gestão da qualidade aplicada na produção de alimentos. Anais..., XXIV Encontro Nacional de Engenharia de Produção, Florianópolis, 2004.

MOREIRA, D. A. Administração da produção e operações. 2.ed. São Paulo: Cengage Learning, 2012. 
MUTHER, R. Systematic Layout Planning. Boston: CBI Publishing Company, Inc, 1961.

MUTHER, R. Systematic Layout Planning. 2.ed. Boston: Cahners Books, 1973.

SANTOS, L. C.; GOHR, C. F.; LAITANO, J. C. A. Planejamento sistemático de layout: adaptação e aplicação em operações de serviços. Revista Gestão Industrial, Paraná, v. 08, n. 01, p. 01-21, 2012.

SILVA, F. F. A.; BANDEIRA, F. M. G.; BARBALHO, W. H. M. O método SLP como base para a proposição de um projeto de arranjo físico: necessidades para melhoria do fluxo de produção de gás, óleo e água de estação coletora e compressora da Petrobrás no rio grande do norte. Anais..., XXX Encontro Nacional de Engenharia de Produção, 2010, São Carlos, 2010.

SLACK, N.; CHAMBERS, S.; JOHNSTON, R. Administração da produção. 3.ed. São Paulo: Atlas, 2009.

TAVARES, L. F.; FERNANDES, T. A. Reestruturação do layout do Laboratório Dietético da Universidade Federal Fluminense: planta física e equipamentos. 2006. Anais..., XIII Simpósio de Engenharia de Produção, 2006, Bauru. 